\title{
Runoff forecasting benefit evaluation for long-term power generation scheduling
}

\author{
Xiaoling Ding ${ }^{1,2}$, Jianzhong Zhou ${ }^{1 *}$, Xiaocong $\mathrm{Mo}^{2}$, Chao Wang ${ }^{3}$, Yongqiang $\mathrm{Wang}^{2}$ \\ ${ }^{1}$ School of Hydropower and Informaiton Engineering, Huazhong University of Science and Techonlogy, Wuhan 430074, China \\ ${ }^{2}$ Changjiang River Scientific Research Institute of Changjiang Water Resource Commission, Wuhan 430074, China; \\ ${ }^{3}$ China Institute of Water Resources and Hydropower Research, Beijing 100038, China
}

\begin{abstract}
Long-term runoff forecasting important reference significance for the long-term planning of cascade hydropower stations. The traditional forecast accuracy evaluation is based on the deviation between the predicted runoff and the measured hydrological sequence, but fails to consider the effect on long-term scheduling. In this paper, a runoff forecasting evaluation method for long-term scheduling is presented. First, a monthly distribution method based on the forecast value of annual runoff is proposed to describe the uncertainty of the forecast. Then, a power generation plan model with the maximum generation objective and an actual generation benefit evaluation model are established to study the effect of runoff forecasting in scheduling. At last two indexes of "Incremental generation" and "Incremental benefit" based on the comparison of actual benefit with and without a forecast plan are given to evaluate the performance of forecasting. The case study shows that the proposed evaluation method can reflect the actual benefit brought by the forecast information, which provide more practical guidance for the hydropower station.
\end{abstract}

\section{Introduction}

In domestic reservoir management, power generation dispatching plan is the basis of future operation, and runoff process is an important input condition of power generation plan. Runoff descriptions for a given year are usually based on measured historical data, statistically generated sequences or forecast time series $^{[1,2,3]}$.Hydrological forecast information has been applied to guide reservoir operation in the existing studies ${ }^{[4,5]}$, and valuable conclusions have been drawn. However, the uncertainty of runoff process has a great influence on the implementation of power generation scheduling, and how to evaluate the performance of forecasting is the key to determine whether the prediction data can be used to guide the scheduling plan. In hydrology, the forecast accuracy is mainly expressed by absolute error, relative error, deterministic coefficient and other indexes ${ }^{[6,7]}$ by calculating the differences between forecast value and measured data, which fails to judge the availability of forecast information based on the objective of operation. Therefore, based on the comparison the actual scheduling results under the unforecasted and the forecasted scheduling plan, two indexes, namely "incremental generation" and "incremental benefit", are put forward to evaluate the runoff forecast benefit quantitatively. Taking Xiluodu-Xiangjiaba cascade hydropower station of Jinsha River as an example for research, the results show that the evaluation method based on dispatching target can better characterize the runoff forecasting effect, and is more conducive for long-term power generation.

\section{Research methodology}

\subsection{Description of the uncertainty of long-term runoff forecasting}

Considering multi period forecast in long-term runoff forecasting is unreliable ${ }^{[4]}$, runoff series is expressed based on annual runoff forecast. In order to describe the uncertainty of the runoff forecast, a monthly distribution method based on the forecast value of annual runoff is proposed. The uniform distribution is applied to describe forecast error of annual runoff. Firstly, the fuzzy-set pair method ${ }^{[8]}$ is used to classify the long series runoff into the wet, normal and dry years. Then the annual runoff amount and the time allocation coefficient are calculated based on the classification. Finally, based on the principle of minimum distance, the grade of the forcasted annual runoff is judged to get the time distribution coefficient, and then the forecast runoff is decomposed into monthly runoff process. With this approach, the runoff process under different forecast errors is simulated under the assumption that error distribution of the annual runoff is uniformed.

\subsection{Generation planning and scheduling evaluation model}

\subsubsection{Generation planning model}


The optimal dispatching model is established for the generation planning with the goal of maximizing power generation of cascade stations, which is solved by DDDP algorithm ${ }^{[9]}$ with the input of the planned runoff process.

The optimal operation process of cascade hydropower stations is determined to maximize the total power generation over the whole periods under the premise initial and final water levels and the constraint conditions of each period.

The objective function is described as follow:

$$
P E=\max \sum_{i=1}^{M} \sum_{t=1}^{T} A_{i} \cdot Q_{i, t} \cdot H_{i, t} \cdot \Delta t
$$

Where $P E$ is the total power generation of the cascade; $t$ is time variable, $T$ is the whole periods; $i$ is hydro station numbering variable, $M$ is the number of stations; $A_{i}$ is comprehensive output coefficient of $i$-th station; $Q_{i, t}$ and $H_{i, t}$ denote water discharge and net water head of the $i$-th station in the $j$-th period, respectively; $\Delta t$ is interval of scheduling term.

The constraints in the process of cascade scheduling are described as follows:

(1) Water level limits

$$
\underline{Z}_{i, t} \leq Z_{i, t} \leq \bar{Z}_{i, t}
$$

(2) Output limits

$$
\underline{N}_{i, t} \leq N_{i, t} \leq \bar{N}_{i, t}
$$

(3) Water discharge limits

$$
\underline{Q}_{i, t} \leq Q_{i, t} \leq \bar{Q}_{i, t}
$$

(4) Water balance equation

$$
V_{i, t+1}=V_{i, t}+\left(I_{i, t}-Q_{i, t}\right) \cdot \Delta t
$$

(5) Hydraulic connection of hydro stations

$I_{i, t}=Q_{i-1, t}+q_{i, t}$

Where $Z_{i, t}, N_{i, t}, Q_{i, t}, V_{i, t}, I_{i, t}, q_{i, t}$ stand for water level, output, water discharge, storage and interval inflow of the $i$-th station in the $t$-th period, respectively; $\underline{Z}_{i, t}, \bar{Z}_{i, t}, \underline{N}_{i, t}, \bar{N}_{i, t}, \underline{Q}_{i, t}, \bar{Q}_{i, t}$ are the minimum and maximun water level limit, output limit and discharge limit of the $i$-th station in the $j$-th period, respectively.

\subsubsection{Scheduling evaluation model}

In the actual scheduling operation, the reservoir runs according to the optimal planned water level generated by generation planning model in 2.2.1. Two evaluation models of power generation and generation benefit are both applied to represent the actual generation scheduling efficiency.

The actual power generation under actual runoff is calculated according to the follow formula.

$$
A E=\sum_{i=1}^{M} \sum_{t=1}^{T} A_{i} \cdot Q_{i, t} \cdot H_{i, t}^{*} \cdot \Delta t
$$

Where $A E$ is the actual power generation of the cascade; $H_{i, t}^{*}$ is the net water head of the $i$-th station in the $j$-th period according to the planned water level in the actual scheduling process.

Considering to the long-term contract trading model of electricity market, the actual generation benefit is evaluated as the follow formula.

$$
A B=P E * p_{0}+(A E-P E) * p_{s}
$$

Where $A B$ stands for the actual power generation benefit of the cascade; $p_{0}$ is the contract price, and $P_{\mathrm{s}}$ is the average spot price.

\subsection{Runoff forecasting benefit evaluation}

The runoff process is divided into three types: forecast runoff, unforecasted runoff and actual runoff, and the first two belong to planned runoff. The forecast runoff is simulated by the proposed method in 2.1.1, the mean annual historical data is taken as the unforecasted runoff without forecast, namely runoff for generation planning without forecast information and the actual runoff process is the historical measured data.

According to the models in 2.2.1, the power generation planning scheme, including planned operation level and planned generation, is worked out. The planned water level without forecast is denoted as $Z_{n o}$, the corresponding generation is denoted as $P E_{n o}$, the planned water level with forecast is recorded as $Z_{p r e}$, and the corresponding generation is recorded as $P E_{\text {pre }}$. Taking the actual runoff as input, the actual generation results are calculated under the operation of $Z_{n o}$ and $Z_{p r e}$ by applying the model in 2.2.2,

The calculation formula of incremental power generation is as follow.

$$
\Delta E=A E_{\text {pre }}-A E_{\text {no }}
$$

Where $\Delta E$ stands for the incremental generation index; $A E_{\text {pre }}$

is the actual power generation under the operation of $Z_{\text {pre }} ; A E_{n o}$ is the actual power generation under the operation if $Z_{\text {no }}$.

The incremental benefit index is calculated as follows.

$$
\Delta B=A B_{\text {pre }}-A B_{n o}
$$

Where $\Delta B$ stands for the incremental benefit index; $A B_{\text {pre }}$ is the actual power generation under the operation of $Z_{p r e} ; A B_{n o}$ is the actual power generation under the operation if $Z_{n o}$.

\section{Case Study}

\subsection{Description of cascade hydro stations}

The Jinsha River is the upper reaches of the Yangtze river in China. The lower reaches of the Jinsha River are provided with the most abundant water resources of the river basin, to reach a total length of $783 \mathrm{~km}$ and drop about $729 \mathrm{~m}$. Xiluodu and Xiangjiaba are the last two cascade hydro stations of the lower reaches of the Jinsha 
River, which play the role of power generation, while improving navigation conditions, taking into account flood control, irrigation and sand retaining functions ${ }^{[10,11]}$. The characteristics of cascade reservoirs are shown in Table 1.

The normal water level is set as the beginning and the end of water level in the scheduling, and flood control level in flood operation.

Table 1 The characteristic parameters of hydro stations

\begin{tabular}{cccccc}
\hline Hydro & $\begin{array}{c}\text { Normal water } \\
\text { level } \\
(\mathrm{m})\end{array}$ & $\begin{array}{c}\text { Flood } \\
\text { contr } \\
\text { ol } \\
\text { station }\end{array}$ & $\begin{array}{c}\text { Dead water } \\
\text { level } \\
(\mathrm{m})\end{array}$ & $\begin{array}{c}\text { Minimu } \\
\mathrm{m}\end{array}$ & $\begin{array}{c}\text { installe } \\
\mathrm{d}\end{array}$ \\
$\mathrm{d}$ & $\mathrm{e}$ & $\begin{array}{c}\mathrm{e} \\
\text { capacit } \\
\left(\mathrm{m}^{3} / \mathrm{s}\right)\end{array}$ & $\begin{array}{c}\mathrm{y} \\
(\mathrm{millio} \\
\mathrm{n} \mathrm{kw})\end{array}$ \\
\hline Xiluodu & 600 & 560 & 540 & 1200 & 13.86 \\
Xiangjiaba & 380 & 370 & 370 & 1200 & 6.4 \\
\hline
\end{tabular}

\subsection{Runoff process simulation and accuracy evaluation}

The runoff at Pingshan Hydrological Station is taken as the inflow of Xiluodu Reservoir. The average monthly runoff from 1956 to 2010 is taken as the planned runoff process without forecast information. Three typical years, 2005, 2009 and 1958, in which the empirical frequency of the reservoir annual inflow was nearly $25 \%, 50 \%$ and $75 \%$, are selected as the representative of the wet, normal and dry years, and different forecast runoff processes were

simulated according to the method of 2.1 on the basis of the actual observed runoff in three typical years.

The historical runoff from 1956 to 2010 is divided into 3 categories including wet years, normal years and dry years, and the average runoff process under each classification is shown as Fig.1. The three average runoff process are used to determine the monthly distribution coefficient for annual runoff under different forecast errors.

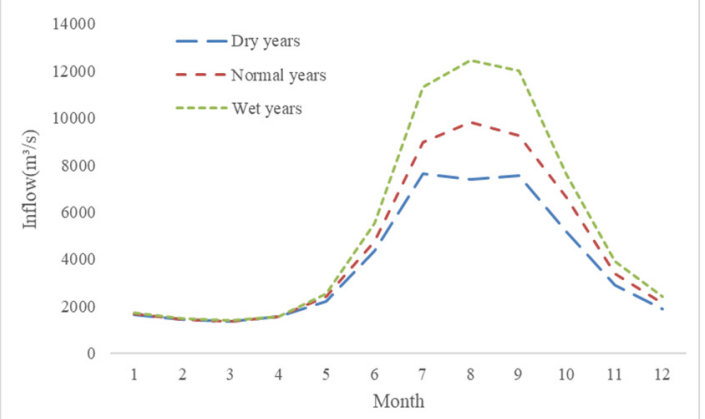

Fig.1. The average runoff process under three runoff classifications

The relative error of annual runoff forecast is set as 0.3 to 0.3 with an interval of 0.1 . The simulated runoff process is shown in Fig.2. The absolute value of monthly relative errors between simulated runoff and measured runoff are calculated, and the mean value is taken as the process error index as shown in Table 2. As can be seen from table 2 , the process errors are different from annual runoff errors in three typical years according to the simulation method presented in this paper.

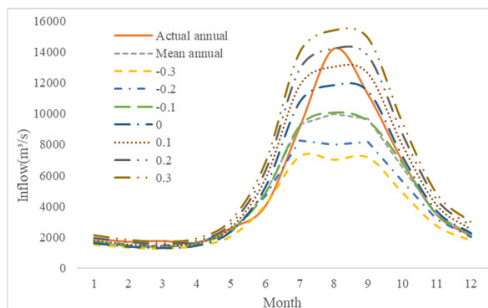

(a)Wet year

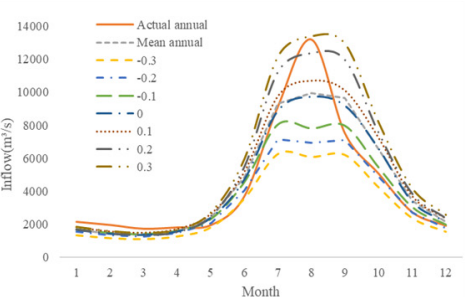

(b)Normal year

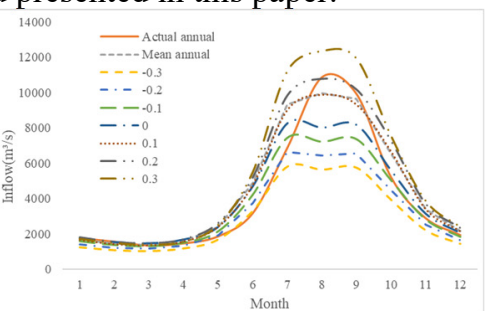

(c)dry year

Fig.2. Planned and actual runoff processes for three typical years

Table 2: Errors between planned runoff and actual runoff in three typical years

\begin{tabular}{cccc}
\hline \multirow{2}{*}{ Relative error of annual runoff } & \multicolumn{3}{c}{ Runoff process error } \\
\cline { 2 - 4 } & Wet year & Normal year & Dry year \\
\hline Mean annual & 0.12 & 0.22 & 0.17 \\
-0.3 & 0.23 & 0.25 & 0.25 \\
-0.2 & 0.15 & 0.18 & 0.17 \\
-0.1 & 0.11 & 0.16 & 0.13 \\
0.0 & 0.14 & 0.21 & 0.16 \\
0.1 & 0.15 & 0.24 & 0.17 \\
0.2 & 0.20 & 0.30 & 0.23 \\
0.3 & 0.28 & 0.34 & 0.27 \\
\hline
\end{tabular}

\subsection{Forecast benefit analysis}

By comparing the results of generation planning and actual scheduling operation under two scenarios of planned runoff, the forecast benefit indexes of three typical years are calculated. The contract price is 0.48 yuan per kwh, and the spot selling price is 0.3 yuan per $\mathrm{kwh}$ when the actual generation is higher than the planned 
capacity, and 0.62 yuan per kwh when lower than the planned capacity. The results of generation and evaluation indexes are shown in Table 3 to Table 5.

As can be seen in Table 3 to Table 5,1) The planned runoff process has obvious influence on the generation planning. Because of the error between the planned and actual runoff process, there is a deviation between the actual generation $(A E)$ and the planned generation $(P E)$ when operating under the planned water level. 2) Comparing $A E$ under operation plan of two scenarios, the $A E$ under forecast plan is less than that without forecast except the annual runoff error of -0.2 in flood year. In normal year, when the annual forecast error is between 0.1 and 0.1 , the $A E$ under forecast plan is more than that without forecast. In the dry year, the $A E$ under the forecast scheme has been reduced. 3) Contrasted with the actual power generation benefit $(A B)$ under the plan without forecast, the $A B$ under forecast plan is increased when the forecast error is between- 0.1 and 0 in wet year, the $A B$ is increased when the forecast error is between -0.2 and 0 in normal year, and in dry year, the $A B$ is increased when the forecast error is between -0.1 and 0.1 . 4) Three typical annual dispatching results indicate that: on the premise that the annual runoff process is difficult to achieve accurate forecast, the annual average runoff is more conducive to the actual operation of generating when the generation capacity is the target; the runoff process with small forecasting error can be used as the guidance for power generation planning when the generation benefit in the contract market is taken as the dispatching objective.

Generally, the relationship between runoff forecast error and two kinds of forecast benefit indexes is not simply positive correlation. In addition to the forecast runoff error, the forecast benefit indexes have a greater relationship with the annual runoff abundance, time distribution and scheduling objectives. The evaluation method with the scheduling objective as the quantitative index can better represent the runoff forecast performance, and is more conducive to providing a reference for longterm power generation plan.

Table 3: Comparison of scheduling results and forecast benefit evaluation for wet year

\begin{tabular}{|c|c|c|c|c|c|c|}
\hline \multirow{2}{*}{$\begin{array}{l}\text { Relative error } \\
\text { of annual } \\
\text { runoff }\end{array}$} & \multirow{2}{*}{$\begin{array}{l}\text { Runoff } \\
\text { process } \\
\text { error }\end{array}$} & $\begin{array}{c}\text { Planned power } \\
\text { generation } \\
P E\end{array}$ & $\begin{array}{c}\text { Actual power } \\
\text { generation } \\
A E\end{array}$ & $\begin{array}{c}\text { Incremental } \\
\text { generation } \\
\Delta E\end{array}$ & $\begin{array}{c}\text { Actual generation } \\
\text { benefit } \\
A B\end{array}$ & $\begin{array}{c}\text { Incremental } \\
\text { benefit } \\
\Delta B\end{array}$ \\
\hline & & (million kwh) & (million kwh) & $\begin{array}{c}\text { (million } \\
\text { kwh) }\end{array}$ & (million yuan) & $\begin{array}{c}\text { (million } \\
\text { yuan) }\end{array}$ \\
\hline No forecast & 0.12 & 91664.65 & 92903.19 & 1 & 44370.59 & 1 \\
\hline-0.3 & 0.23 & 79607.17 & 92903.17 & -0.02 & 42200.24 & -2170.35 \\
\hline-0.2 & 0.15 & 87830.41 & 92903.68 & 0.49 & 43680.58 & -690.02 \\
\hline-0.1 & 0.11 & 92670.33 & 92897.55 & -5.64 & 44549.93 & 179.33 \\
\hline 0.0 & 0.14 & 93298.32 & 92903.04 & -0.15 & 44538.12 & 167.53 \\
\hline 0.1 & 0.15 & 96738.37 & 92828.25 & -74.94 & 44010.15 & -360.45 \\
\hline 0.2 & 0.20 & 99650.43 & 92830.63 & -72.56 & 43603.93 & -766.66 \\
\hline 0.3 & 0.28 & 102453.69 & 92876.21 & -26.98 & 43239.73 & -1130.86 \\
\hline
\end{tabular}

Table 4: Comparison of scheduling results and forecast benefit evaluation for normal year

\begin{tabular}{|c|c|c|c|c|c|c|}
\hline \multirow{2}{*}{$\begin{array}{l}\text { Relative error } \\
\text { of annual } \\
\text { runoff }\end{array}$} & \multirow{2}{*}{$\begin{array}{l}\text { Runoff } \\
\text { process } \\
\text { error }\end{array}$} & $\begin{array}{l}\text { Planned power } \\
\text { generation } \\
P E\end{array}$ & $\begin{array}{c}\text { Actual power } \\
\text { generation } \\
A E\end{array}$ & $\begin{array}{c}\text { Incremental } \\
\text { generation } \\
\Delta E\end{array}$ & $\begin{array}{c}\text { Actual generation } \\
\text { benefit } \\
A B\end{array}$ & $\begin{array}{c}\text { Incremental } \\
\text { benefit } \\
\Delta B\end{array}$ \\
\hline & & (million kwh) & (million kwh) & $\begin{array}{c}\text { (million } \\
\text { kwh) }\end{array}$ & (million yuan) & $\begin{array}{c}\text { (million } \\
\text { yuan) }\end{array}$ \\
\hline No forecast & 0.22 & 91664.65 & 83385.98 & 0.00 & 38866.26 & 0.00 \\
\hline-0.3 & 0.25 & 69744.22 & 83323.28 & -62.71 & 37550.94 & -1315.32 \\
\hline-0.2 & 0.18 & 79152.26 & 83385.91 & -0.07 & 39263.18 & 396.92 \\
\hline-0.1 & 0.16 & 86547.72 & 83386.69 & 0.70 & 40594.60 & 1728.34 \\
\hline 0.0 & 0.21 & 90728.56 & 83386.15 & 0.17 & 38997.42 & 131.16 \\
\hline 0.1 & 0.24 & 95587.99 & 83386.69 & 0.70 & 38317.43 & -548.83 \\
\hline 0.2 & 0.30 & 94861.73 & 83375.18 & -10.80 & 38411.97 & -454.29 \\
\hline 0.3 & 0.34 & 97620.40 & 83359.69 & -26.29 & 38016.15 & -850.11 \\
\hline
\end{tabular}

Table 5: Comparison of scheduling results and forecast benefit evaluation for dry year

\begin{tabular}{|c|c|c|c|c|c|c|}
\hline \multirow{2}{*}{$\begin{array}{l}\text { Relative error } \\
\text { of annual } \\
\text { runoff }\end{array}$} & \multirow{2}{*}{$\begin{array}{l}\text { Runoff } \\
\text { process } \\
\text { error }\end{array}$} & $\begin{array}{c}\text { Planned power } \\
\text { generation } \\
P E\end{array}$ & $\begin{array}{c}\text { Actual power } \\
\text { generation } \\
A E\end{array}$ & $\begin{array}{l}\text { Incremental } \\
\text { generation } \\
\Delta E\end{array}$ & $\begin{array}{c}\text { Actual generation } \\
\text { benefit } \\
A B\end{array}$ & $\begin{array}{c}\text { Incremental } \\
\text { benefit } \\
\Delta B\end{array}$ \\
\hline & & (million kwh) & (million kwh) & $\begin{array}{c}\text { (million } \\
\text { kwh) }\end{array}$ & (million yuan) & $\begin{array}{c}\text { (million } \\
\text { yuan) }\end{array}$ \\
\hline No forecast & 0.17 & 91664.65 & 83310.73 & 0.00 & 38819.60 & 0.00 \\
\hline-0.3 & 0.25 & 64431.49 & 83270.94 & -39.79 & 36578.95 & -2240.65 \\
\hline-0.2 & 0.17 & 73460.90 & 83297.91 & -12.82 & 38212.34 & -607.26 \\
\hline-0.1 & 0.13 & 81686.95 & 83297.44 & -13.29 & 39692.88 & 873.28 \\
\hline
\end{tabular}




\begin{tabular}{llllllc}
0.0 & 0.16 & 88006.12 & 83310.56 & -0.17 & 40834.27 & 2014.67 \\
0.1 & 0.17 & 91587.22 & 83310.50 & -0.23 & 38830.30 & 10.70 \\
0.2 & 0.23 & 95860.92 & 83310.56 & -0.17 & 38232.02 & -587.58 \\
0.3 & 0.27 & 94866.49 & 83298.69 & -12.04 & 38363.88 & -455.72 \\
\hline
\end{tabular}

\section{Conclusion}

A practical method is provided to evaluate the performance of runoff forecast for power generation dispatching. The experimental results show that the smaller forecast error will bring better scheduling benefit in general. However, on the premise that the annual runoff process is difficult to achieve accurate forecasting, it is necessary to take the dispatching objective as the direction to analyze the forecast efficiency comprehensively. On basis of this research, further study on the characteristics of forecasting benefit under uncertainties by combining long series historical runoff data will have more practical significance for the hydropower stations to utilize the forecast information scientifically.

\section{References}

1. Zambelli M S, Luna I, Soares S. Long-term hydropower scheduling based on deterministic nonlinear optimization and annual inflow forecasting models[C]// PowerTech, 2009 IEEE Bucharest. IEEE, 2009:1-8.

2. Kalteh A M. Monthly river flow forecasting using artificial neural network and support vector regression models coupled with wavelet transform[J]. Computers \& Geosciences, 2013, 54(4):1-8.

3. Wang W C, Kwokwing C, Xu D M, et al. Improving forecasting accuracy of annual runoff time series using ARIMA based on EEMD decomposition. Water Resources Management, 2015, 29(8): 2655-75.

4. Xie M, Zhou J, Li C, et al. Long-term generation scheduling of Xiluodu and Xiangjiaba cascade hydro plants considering monthly streamflow forecasting error[J]. Energy Conversion \& Management, 2015, 105:368-376.

5. Wang B, Zhang J. Risk analysis on classified forecast dispatching mode based on stochastic simulative method[J]. Journal of Hydroelectric Engineering, 2009, 28(2):8-13.

6. Wu J, Zhou J, Chen L, et al. Coupling Forecast Methods of Multiple Rainfall-Runoff Models for Improving the Precision of Hydrological Forecasting[J]. Water Resources Management, 2015, 29(14):5091-5108.

7. Zhu S, Zhou J, Ye L, et al. Streamflow estimation by support vector machine coupled with different methods of time series decomposition in the upper reaches of Yangtze River, China[J]. Environmental Earth Sciences, 2016, 75(6):531.
8. Ding X, Zhou J, Lu C, et al. Approach to annual runoff classification based on fuzzy set theory and set pair analysis $[\mathrm{J}]$. Journal of Hydroelectric Engineering, 2015, 34(5):4-9. (in chinese)

9. Li C, Zhou J, Ouyang $\mathrm{S}$, et al. Improved decomposition-coordination and discrete differential dynamic programming for optimization of large-scale hydropower system[J]. Energy Conversion \& Management, 2014, 84:363-373.

10. Zhang R, Zhou J, Yuan L, Zhang Y (2013). Study on dry season operation of cascade reservoir in Jinsha River. Journal of Hydraulic Engineering, 44(12), 1399-1408.(in chinese)

11. Wang C, Zhou J, Peng L, et al. Long-term scheduling of large cascade hydropower stations in Jinsha River, China[J]. Energy Conversion \& Management, 2015, 90(2015):476-487. 